\title{
Signos de envejecimiento acelerado en los ratones transgénicos que sobreexpresan IKKa en el núcleo.
}

\author{
Verónica García-García ${ }^{a}$, Josefa P. Alameda, Federico Sánchez-Sierra, Pilar Hernández, \\ Rosa A. García, Angustias Page, M. L. Casanova
}

CIEMAT-CIBERONC.

a. veroga03@ucm.es

IV Congreso de Señalización Celular, SECUAH 2019.

20-22 de marzo, 2019. Universidad de Alcalá. Alcalá de Henares, Madrid. España

Sesión de paneles.

Keywords: Ikkalpha, ratones transgénicos, envejecimiento prematuro, piel, cáncer

\section{Abstract}

En nuestro grupo hemos generado ratones transgénicos que, bajo el control de los elementos reguladores de la queratina $\mathrm{K} 5$, expresan la proteína IKKa humana en el núcleo de las células de la capa basal de los epitelios estratificados de la piel y de otros órganos internos (ratones que denominamos K5-N-IKKa). El objetivo de este trabajo ha sido caracterizar el fenotipo que presentan estos ratones en estos tejidos como consecuencia de la expresión del transgén. Se han realizado estudios histológicos e inmunohistoquimicos de diferentes tejidos que han mostrado que la sobreactivación de IKKa en el núcleo provoca un fenotipo de envejecimiento prematuro en piel, caracterizado por la presencia de atrofia epidérmica junto a áreas de hiperplasia papilomatosa (dando el aspecto de arrugas), reducción del panículo adiposo y atipia de las células basales (considerada como signo de premalignidad); en la dermis se observa además inflamación con abundantes mastocitos, así como focos de inflamación liquenoide. Adicionalmente, hemos detectado el desarrollo de tumores espontáneos de diverso origen, principalmente carcinomas escamosos de piel, adenocarcinomas de pulmón y linfomas no Hodgkin de células B. Hemos obtenido los mismos resultados cuando se expresa N-IKKa en ratones deficientes en IKKa. En conjunto, las alteraciones que desarrollan los ratones que sobreexpresan IKKa en el núcleo son semejantes a las que se observan en la vejez en humanos.

Citation: García-García, Verónica; Alameda, Josefa P.; Sánchez-Sierra, Federico; Hernández, Pilar; García, Rosa A.; Page, Angustias; Casanova, M. L. (2019) Signos de envejecimiento acelerado en los ratones transgénicos que sobreexpresan IKKa en el núcleo. Proceedings of the IV Congreso de Señalización Celular, SECUAH 2019. 20-22 de marzo, 2019. Universidad de Alcalá. Alcalá de Henares, Madrid. España. Sesión de paneles. dianas 8 (1): e201903p04. ISSN 1886-8746 (electronic) journal.dianas.e201903p04 http://www3.uah.es/dianas?e201903p04. URI http://hdl.handle.net/10017/15181

Copyright: @ García-García V, Alameda JP, Sánchez-Sierra F, Hernández P, García RA, Page A, Casanova ML. Some rights reserved. This is an open-access work licensed under a Creative Commons Attribution-NonCommercial-NoDerivatives 4.0 International License. http://creativecommons.org/licenses/by-nc$\mathrm{nd} / 4.0 /$ 